\title{
Proposition of Thin-Layer Repairing Methods Using Low-Elasticity Polymer Portland Cement Materials and Glue and Study on the Fatigue Resistance of Reinforced Concrete Slab
}

\author{
Tadashi Abe $\mathbb{D}^{1}{ }^{1}$ Kiyoshi Ito, ${ }^{2}$ Noriyuki Kozakai, ${ }^{3}$ and Takayoshi Kodama ${ }^{4}$ \\ ${ }^{1}$ College of Industrial Technology, Nihon University, Narashino City, Chiba 275-8575, Japan \\ ${ }^{2}$ Nihon University Graduate School of Engineering, Nihon University, Narashino City, Chiba 275-8575, Japan \\ ${ }^{3}$ Construction Materials Division, Sumitomo Osaka Cement Co., Ltd, Chiyoda-ku, Tokyo 102-8465, Japan \\ ${ }^{4}$ Technical Sales Division, Kajima Road Co., Ltd, Bunkyo-ku, Tokyo 112-8566, Japan \\ Correspondence should be addressed to Tadashi Abe; abe.tadashi@nihon-u.ac.jp
}

Received 3 March 2018; Revised 2 September 2018; Accepted 13 September 2018; Published 29 November 2018

Guest Editor: Rishi Gupta

Copyright (C) 2018 Tadashi Abe et al. This is an open access article distributed under the Creative Commons Attribution License, which permits unrestricted use, distribution, and reproduction in any medium, provided the original work is properly cited.

In this repair method, two types of adhesives, such as a penetrable adhesive and a high-durability adhesive, were applied to the adhesion interface of the materials to be repaired, and then cast. The repair method was then evaluated for fatigue resistance using wheel load running tests. It was developed to ensure the long-term integrity of the repair material and RC slabs. The results of the experiments confirmed that this repair method provides significantly better fatigue resistance than the conventional construction method. Moreover, this study proposes two wet repair cycles and one dry repair cycle with reinforcement measures to improve the load-bearing performance.

\section{Introduction}

Most of the Japanese road bridges were built between 1950 and 1970 . By 2026, 46\% of these bridges will be 50 years old or older, making the maintenance and management of aging bridges an important issue $[1,2]$. Furthermore, implementation of waterproofing for the RC slabs was delayed. In fact, waterproofing in the design and during maintenance was required for expressways in 1988, but it was required for general national roads only after the road bridge specification was revised in 2002 [3]. For this reason, the upper surface of RC slabs covered with about $80 \mathrm{~mm}$ of asphalt pavement gets wet from rainwater and the damage from traffic load is accelerated. It was left untouched, and the damage due to cracks and potholes in the asphalt pavement has been left unrepaired. Japan is an elongated archipelago surrounded by water and has a varied climate with cold and temperate regions. As a result, bridges are affected by airborne salt near the coastline and by damage by salt attack. Bridges are also affected by freezing damage from the snow-melting and antifreezing agents that are used in snowy areas. Particularly in snowy cold regions, reinforcing bars become corroded, and the spraying of snow-melting agents and antifreezing agents causes daily freeze-thawing action. These factors accelerate damage to the concrete. As a result, the top surface concrete of RC slabs has been degraded into aggregate due to corrosion of the reinforcement caused by salt damage and due to freeze-thaw damage, and some of them have been removed after about 30 years of service. Moreover, a repair site can be redamaged and the damage can spread, resulting in the need to replace the RC slabs. The method for repairing a part of an RC slab when cracking has occurred or limestone has exuded from the asphalt is to remove the asphalt paving, and the part of the concrete that has degraded into aggregate is removed using a paving breaker. After removing the concrete, repair of the damaged part is carried out using a cementitious material such as an ultrarapid hardening nonshrink polymer cement mortar or ultrarapid hardening concrete. Finally, curing and waterproofing are carried out, and the asphalt paving is replaced. However, RC slabs are repaired with a thin layer of thickness of about $30 \mathrm{~mm}$, so cracking is quickly caused by wheel loads 
TABLE 1: Composition of repair materials.

\begin{tabular}{|c|c|c|c|c|c|}
\hline & & & & Unit content of water $\left(\mathrm{kg} / \mathrm{m}^{3}\right)$ & Water bonding ratio (\%) \\
\hline \multirow{7}{*}{ U-M-36 } & \multirow{7}{*}{ Premix powder } & \multirow{3}{*}{ Mixed material } & Ultrarapid hardening cement & 925 & \multirow{7}{*}{36} \\
\hline & & & Calcium hydrate & 13 & \\
\hline & & & Water reducer & 2 & \\
\hline & & \multirow[t]{4}{*}{ Other } & Acrylic polymer powder & 0 & \\
\hline & & & Silica sand & 937 & \\
\hline & & & Fiber & - & \\
\hline & & & Water & 338 & \\
\hline \multirow{7}{*}{ U-FM-45 } & \multirow{7}{*}{ Premix powder } & \multirow{2}{*}{ Mixed material } & Ultrarapid hardening cement & 581 & \multirow{7}{*}{48} \\
\hline & & & Calcium hydrate & 37 & \\
\hline & & \multirow{5}{*}{ Other } & Water reducer & 1 & \\
\hline & & & Acrylic polymer & 6 & \\
\hline & & & Silica sand & 1225 & \\
\hline & & & Fiber & 5 & \\
\hline & & & Water & 296 & \\
\hline
\end{tabular}

due to the difference in elastic coefficients of the RC slab concrete and the repair material. Also, there have been many examples where peeling or cracking has occurred at the boundary between the existing RC slab and the repair layer, so repair was carried out again. Therefore, there is an urgent need to develop repair materials suitable for top surface damage of RC slabs and repair techniques capable of ensuring durability, because there is a concern that new cracks may occur due to the impact of a breaker used for cutting concrete in repair work. In this study, we examined the soundness of the adhesion interface of the existing RC slabs, the adhesion strength between repair materials and existing $\mathrm{RC}$ slabs, and the measures to be taken with attention to the repair materials. Wheel load running tests were conducted to evaluate the fatigue resistance of the repair material used in the conventional repair method and in the repair method proposed in this research. The repair technique using repair material developed exclusively for repairing RC slabs (fiber-reinforced, ultrahard, nonshrink, and polymer cement mortar) and the two types of adhesive (penetrable primer and highly durable epoxy resin adhesive) can reinforce the fine cracks in the RC slabs and integrate the repair material and the RC slabs. The repair technique ensures long-term durability and extends the repair cycle, thereby extending the service life of the bridge.

\section{Materials and Methods}

\subsection{Material Properties of Repair Materials}

2.1.1. Ultrarapid, Hardening, Nonshrink Polymer Cement Mortar. In Japan, road maintenance and repair work is restricted to about 8 hours. Rapid construction is required to demolish and remove road materials, repair the road, and release traffic from regulation within 8 hours. For this reason, an ultrarapid, hardening, nonshrink polymer cement mortar is used for the partial repair of conventional RC slabs. The materials of this cementitious mixture were mainly ultrarapid hardening cement and calcium hydrate, but in addition silica sand and water reducer were used. The curing characteristics of this repair material are as follows: initial setting time, 17 minutes; initial strength development, $45.2 \mathrm{~N} / \mathrm{mm}^{2}$ after 3 hours of aging; and static elastic modulus, $43.7 \mathrm{kN} / \mathrm{mm}^{2}$ after 28 days of aging. Since this pot life is 30 minutes or less, prompt work is required. Note that this repair material is described as U-M-36 and is a conventional construction material. The compounding conditions are listed in Table 1. The expression intensity of U-M-36 is shown in Table 2.

\subsubsection{Ultrahard, Fiber-Reinforced Polymer Cement Mortar.} The ultrahard, fiber-reinforced polymer cement mortar is a new repair material. The materials of this cementitious mixture were mainly ultrarapid hardening cement and calcium hydrate, but in addition silica sand, water reducer, and acrylic polymer powder were used. This repair material is called UFM-45. The compounding conditions are listed in Table 1. This repair material was premixed with high-strength vinylon fiber (fiber length: $12 \mathrm{~mm}$ ). By setting the elastic coefficient to about the same as that of the existing RC slabs, resistance to cracking was improved. The material properties are as follows: curing, 45 minutes at setting completion time; compressive strength at 3 hours, $24.5 \mathrm{~N} / \mathrm{mm}^{2}$; and static elastic modulus at 28 days, $23.8 \mathrm{kN} / \mathrm{mm}^{2}$. Therefore, compared with the ultrafast, hard, nonshrink mortar, adequate construction time is secured and cracking of thin-layer repairs is reduced. Table 2 shows the strength development of U-FM-45, and Figure 1 shows the relationship between compressive strength and static elastic modulus.

2.1.3. High-Durability Epoxy Resin Adhesive. A highly durable epoxy resin adhesive (hereinafter referred to as "bonding agent for placing") is applied to a penetrable adhesive that strengthens the adhering surface after damage. This firmly fixes the repairing material to the slab. This adhesive for adhesion was developed to help prevent fatigue in the steel deck $[4,5]$. As reinforcement of the $\mathrm{RC}$ slab, it has been evaluated for its reinforcing effect by the bonding agent for 
TABLE 2: Characteristic values of repair materials.

\begin{tabular}{lccc}
\hline Test items & & $\mathrm{U}-\mathrm{M}-36$ & U-FM-45 \\
\hline \multirow{2}{*}{ Setting time } & Initial setting & $17 \mathrm{~min}$ & $35 \mathrm{~min}$ \\
& Final setting & $25 \mathrm{~min}$ & $45 \mathrm{~min}$ \\
\hline & 2 hours & $25.1 \mathrm{~N} / \mathrm{mm}^{2}$ & $19.1 \mathrm{~N} / \mathrm{mm}^{2}$ \\
\multirow{2}{*}{ Compressive strength } & 3hours & $45.2 \mathrm{~N} / \mathrm{mm}^{2}$ & $24.5 \mathrm{~N} / \mathrm{mm}^{2}$ \\
& 4 hours & $52.3 \mathrm{~N} / \mathrm{mm}^{2}$ & $27.1 \mathrm{~N} / \mathrm{mm}^{2}$ \\
& 28th & $62.3 \mathrm{~N} / \mathrm{mm}^{2}$ & $49.9 \mathrm{~N} / \mathrm{mm}^{2}$ \\
\hline Young's modulus & 28th & $43.7 \mathrm{kN} / \mathrm{mm}^{2}$ & $23.8 \mathrm{kN} / \mathrm{mm}^{2}$ \\
\hline
\end{tabular}

\begin{tabular}{lcc}
\hline Concrete's age (Days) & Compressive strength $\left(\mathrm{N} / \mathrm{mm}^{2}\right)$ & Static elastic modulus $\left(\mathrm{kN} / \mathrm{mm}^{2}\right)$ \\
\hline 0.125 & 29 & 23.8 \\
1 & 36.4 & 24.1 \\
7 & 51.4 & 26 \\
28 & 52.7 & 26.4 \\
\hline
\end{tabular}

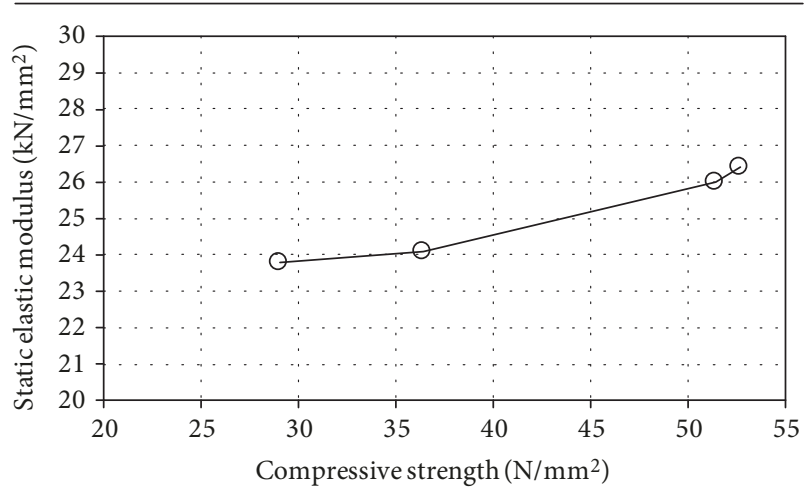

FIgURE 1: Relationship between compressive strength and static elastic modulus.

placing technique $[6,7]$. An epoxy resin is a general term for a compound that contains two or more epoxides (oxiranes) in one molecule, and epoxy resin adhesives are epoxy resins in which denatured hardening agents and subsidiary materials are added and adjusted. The main features of the hardening agents used for epoxy resin adhesives and examples of typical subsidiary materials are summarized in Tables 3 and 4 , respectively.

In the civil engineering field, bonding technologies using epoxy resin adhesives are applied in the precast concrete block method, in construction joints, in the steel plate bonding method, and in the CFRP bonding method. Also, the hardening agent used in these cases is almost always a polyamine type or a polyamine type combined with a polythiol (mercaptan) type. Table 5 lists the material property values of the adhesive for joining.

2.1.4. Penetrable Adhesive. When repairing the RC slab, a breaker is used to remove the damaged and associated fragile areas. The periphery becomes fragile due to fine cracks generated by the impact vibration of this breaker. A permeable adhesive has been developed and applied in order to reinforce the fine cracks generated by the shock vibration of this breaker [8]. This permeable adhesive was newly developed specially for the repair of RC slabs, with the viscosity adjusted so as to permeate fine cracks without using special equipment. The penetrative adhesive was compounded using as the main component a highly durable epoxy resin adhesive developed for fresh concrete construction joints, and adjusted so that the viscosity is lowered. The material properties of the permeable adhesive are listed in Figure 1. Figure 2 shows the status of the penetration in the test specimen U-M-36 that was coated with a permeable adhesive, after destruction.

2.2. Specification of Slab Specimen. A 3/5-scale model of the actual bridge has the following slab dimensions: length, $1600 \mathrm{~mm}$; spacing, $1400 \mathrm{~mm}$; and slab thickness, $150 \mathrm{~mm}$. Based on the road bridge specifications for 2002 issued by the Japan Road Association, the reinforcing bars were made of SD 295A D13 as a double reinforcing bar arrangement. Then, D13 was arranged at $120 \mathrm{~mm}$ intervals in the direction perpendicular to the axis of the tensile side and in the axial direction, and $1 / 2$ of the amount of tensile reinforcement was placed on the compression side. Figure 3 shows the dimensions of the slab, the rebar arrangement map, and the wheel load running fatigue testing machine. The concrete consisted of ordinary Portland cement, crushed sand $(5 \mathrm{~mm}$ or less), and crushed stone ( $5 \mathrm{~mm}$ to $20 \mathrm{~mm}$ ). The compressive strength of the concrete is $35 \mathrm{~N} / \mathrm{mm}^{2}$, the yield strength of the reinforcing bar is $377 \mathrm{~N} / \mathrm{mm}^{2}$, and the tensile strength is $511 \mathrm{~N} / \mathrm{mm}^{2}$.

\subsection{Wheel Load Running Tests}

2.3.1. Wheel Load Running Test Method. For the evaluation of fatigue resistance, the equivalent number of wheel loading cycles in a fatigue testing machine is used. In the wheel load running tests, a wheel load is repeatedly applied to the upper surface of the RC slabs and the repaired RC deck plate within a width of $300 \mathrm{~mm}$ for $1000 \mathrm{~m}$ in the axial direction. The wheel load starts traveling with an initial load of $100 \mathrm{kN}$. Loads are then added in increments of $20 \mathrm{kN}$ every 20,000 runs. Deflection is measured for every 5000 runs when wheel loading runs are once, 10 times, 100 times, 1000 times, 5000 times, and more. A frame $600 \mathrm{~mm}$ in width and $1200 \mathrm{~mm}$ in length was placed around the wheel's traveling position to be filled with water. Wheel loading is performed under wet conditions after the first and second repairs. Holes $9 \mathrm{~mm}$ in diameter were drilled in several repair interfaces in order to observe fluctuations in the water level and check for 
TABLE 3: Classification of hardening agents used for epoxy resin adhesives.

\begin{tabular}{|c|c|}
\hline Classification & Features \\
\hline \multirow{6}{*}{ Polyamine type hardening agents } & $\begin{array}{l}\text { Aliphatic polyamine: the reaction is fast and heat generation is remarkable. Durable to water } \\
\text { and organic solvent. Good adhesion. }\end{array}$ \\
\hline & $\begin{array}{l}\text { Aliphatic polyamine: the reaction is fast and heat generation is remarkable. Durable to water } \\
\text { and organic solvent. Good adhesion. }\end{array}$ \\
\hline & Polyamide: long pot life and low cost \\
\hline & Epoxy-adducted polyamine: high viscosity (useful to viscosity control). \\
\hline & Mannich-modified polyamine: good to low-temperature hardening. \\
\hline & $\begin{array}{l}\text { Polythiol: good to low-temperature hardening polymer network structures are looser than } \\
\text { those of polyamine. High water adsorption. Low durability to water. }\end{array}$ \\
\hline \multirow[t]{2}{*}{ Catalysts } & Tertiary amine: catalyst of polyamine and as catalysts of polyamine and polyamide amine. \\
\hline & Imidazole: reacts as hardening agents and as catalysts of anhydride hardening agents. \\
\hline
\end{tabular}

TABLe 4: Typical submaterials for epoxy resin adhesive.

\begin{tabular}{lc}
\hline & Classification \\
\hline $\begin{array}{l}\text { Additives to give functions } \\
\text { Others }\end{array}$ & Aliphatic polyamine: the reaction is fast and heat generation is remarkable. Durable to water and organic \\
solvent. Good adhesion. \\
Pigments, dyestuff
\end{tabular}

TABLE 5: Material characteristic value of adhesive.

\begin{tabular}{|c|c|c|}
\hline Test items & Penetrable adhesive & High-durability adhesive \\
\hline \multirow{3}{*}{$\begin{array}{lr}\text { Appearance } & \begin{array}{c}\text { Base compound } \\
\text { Curing agent }\end{array} \\
\text { Mixing ratio (main agent: curing agent) }\end{array}$} & Transparent liquid & White paste \\
\hline & Transparent liquid & Blue liquid \\
\hline & $10: 3$ & $5: 1$ \\
\hline Specific gravity of cured product & 1.2 & 1.42 \\
\hline Compressive strength & $104.4 \mathrm{~N} / \mathrm{mm}^{2}$ & $102.9 \mathrm{~N} / \mathrm{mm}^{2}$ \\
\hline Compressive modulus of elasticity & $3172 \mathrm{~N} / \mathrm{mm}^{2}$ & $3976 \mathrm{~N} / \mathrm{mm}^{2}$ \\
\hline Flexural strength & $92.8 \mathrm{~N} / \mathrm{mm}^{2}$ & $41.6 \mathrm{~N} / \mathrm{mm}^{2}$ \\
\hline Tensile shear strength & $58.2 \mathrm{~N} / \mathrm{mm}^{2}$ & $14.9 \mathrm{~N} / \mathrm{mm}^{2}$ \\
\hline Concrete adhesion strength & $2.6 \mathrm{~N} / \mathrm{mm}^{2}$ & $\begin{array}{c}3.7 \mathrm{~N} / \mathrm{mm}^{2} \text { or more of destruction in } \\
\text { the base material }\end{array}$ \\
\hline
\end{tabular}

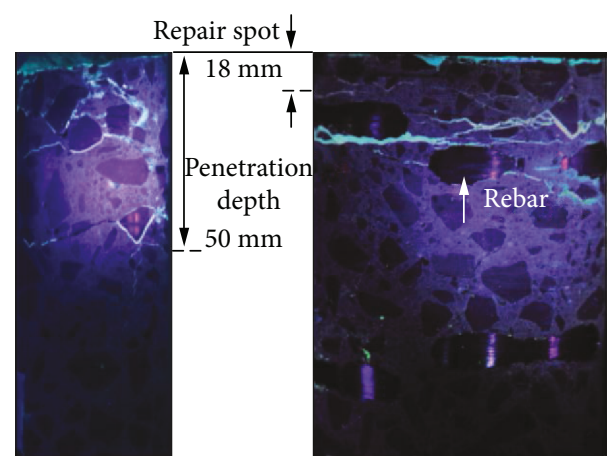

FIGURE 2: Result of permeation verification after specimen RC-U-36 destruction. (1) Diameter $50 \mathrm{~mm}$. (2) Diameter $100 \mathrm{~mm}$.

delamination. The specifications for the water filling is shown in Figure 4.

2.3.2. Repair Method and Repair Cycle. The specimen used in this experiment reproduced the damaged state in the actual
RC slab. In the place where damage such as potholes repeatedly occurred on the asphalt pavement of the RC slab, when the asphalt pavement is removed, the concrete is separated into aggregate and sand (Figure 5(a)) and is in a fragile state. This weakened area was scraped off with a breaker accompanied by striking and vibration (Figure 5(b)) and was finished into a healthy and strong surface (Figure 5(c)). This area was then repaired with an ultrarapid hardening nonshrink polymer cement mortar or ultrarapid hardening concrete agent (Figure 5(d)), and water proofing was carried out. In order to reproduce such a state, the initial loading of the slab specimen was added to reproduce the condition requiring repair. From the previous research, it was determined that repair is required when a deflection corresponding to $1 / 400$ of the span length occurs and two-way cracking is developed on the lower surface of the slab [9-11]. The repair method was verified using a slab surface test specimen subjected to this initial loading. The experimental situation is shown in Figure 6. Using the repair material U-M-36 of the conventional construction method, a breaker was used to break the 


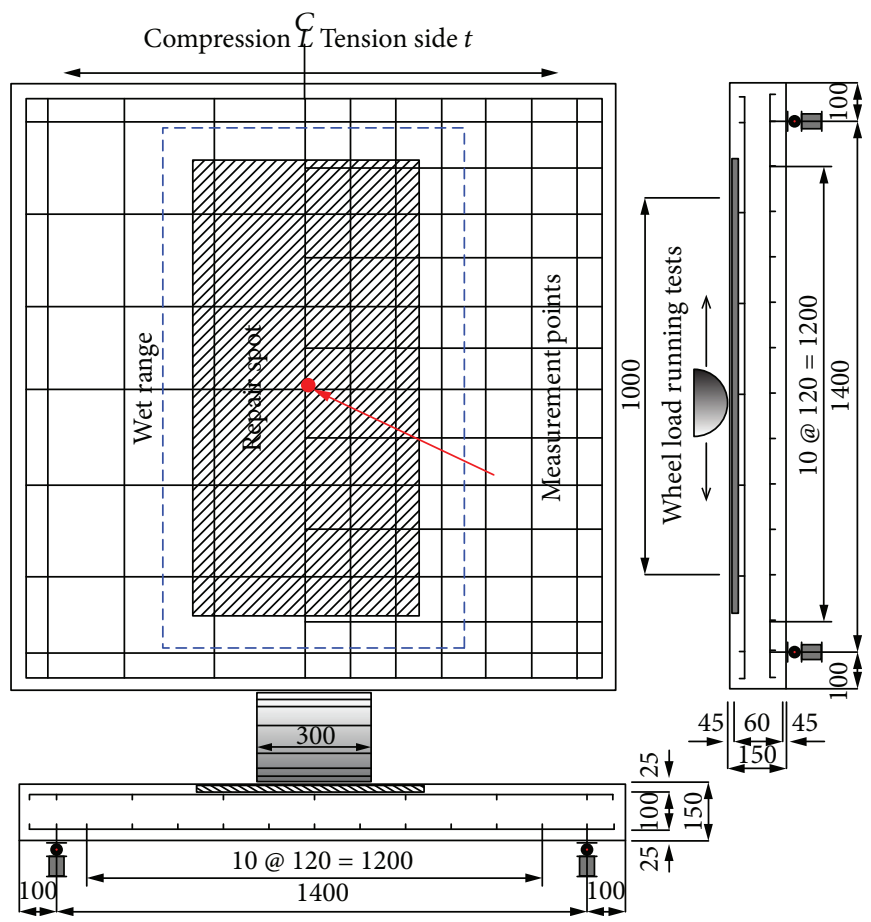

Figure 3: Dimensions of test specimen and plumbing diagram.

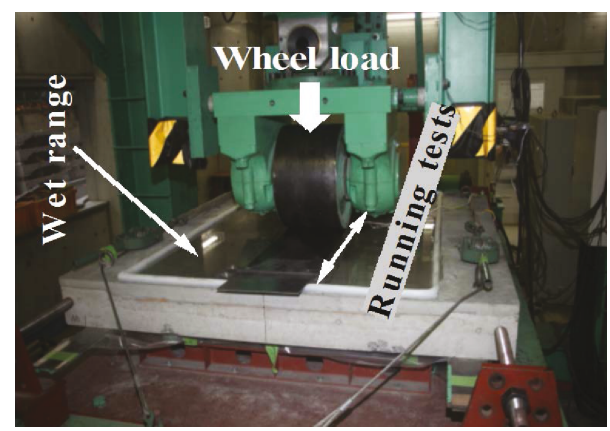

FIGURE 4: Appearance of running load fatigue testing machine and the specifications for the water filling.

repair area (Figures 6(a) and 6(b)), clean the surface, apply the repair material U-M-36, and then finish the surface. Next, in the work procedure of the repair method using the repair material U-FM-45 proposed in this research, a permeable adhesive is applied first to the adhesion interface which was scratched and cleaned, and the bonding agent for joining is repeatedly painted (Figures 6(c) and 6(d)). Then, the repair material U-FM- 45 was poured onto the surface and the finish was the applied (Figure 6(e)). The cycle of repair and running wheel load tests was conducted twice under wet conditions and once under dry conditions. In the two wet-condition cycles, repair was performed when the wheel load caused unevenness or scaling or when the deflection reached $1 / 400$ of the slab span $L$. The dry-condition cycle was performed until punching shear fracture occurred. Fatigue resistance is determined from the cumulative number of equivalent cycles obtained from these three tests.
2.3.3. Number of Equivalent Cycles in Running Fatigue Test. The wheel load running fatigue test uses a step load that increases every twenty thousand runs, and the equivalent running number is calculated to evaluate fatigue resistance. Assuming that the Miner's rule is applicable to the number of equivalent cycles, it is given by (1) [12]. Reference load $P$ in (1) is set at $72 \mathrm{kN}$, which takes into consideration a safety factor of 1.2 based on $3 / 5$ of the design active load, to calculate the equivalent traveling number. The value of 12.7, as proposed by Matsui, is applied to the absolute value of the reciprocal $m$ of the slope of the SN curve.

$$
N_{e q}=\sum_{i=1}^{n}\left(P_{i} / P\right)^{m} \times n_{i}
$$

The equation is expressed as follows: $P_{i}$ is the loaded load $(\mathrm{kN}), P$ is the reference load $(=72 \mathrm{kN}), n_{i}$ is the number of experiment runs (times), and $m$ is the reciprocal of the slope of the SN curve.

\section{Results}

3.1. Number of Equivalent Cycles. Table 6 lists the number of equivalent cycles and the reinforced equivalent running number used in this study.

3.1.1. Specimen RC-U-36 Using Conventional Repair Material $U-M-36$. The number of equivalent cycles of the initial loading is $7.865 \times 10^{6}$. With the repair material U-M-36 with wheel loading under wet conditions in the first cycle, the number of equivalent cycles in the running wheel load running tests is $1.685 \times 10^{6}$. Similarly, the number of equivalent cycles of the 2 nd repair cycle is $1.621 \times 10^{6}$. The number 


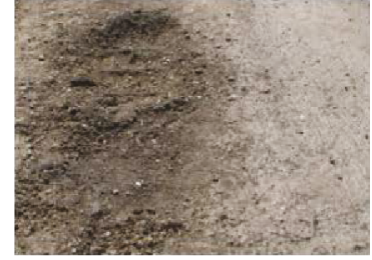

(a)

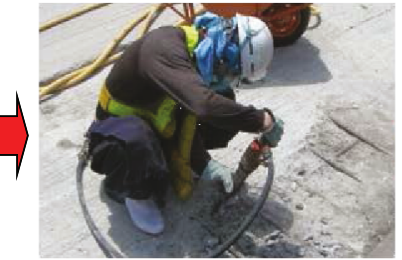

(b)

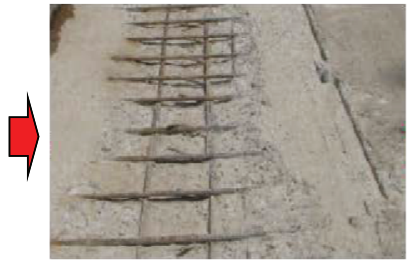

(c)

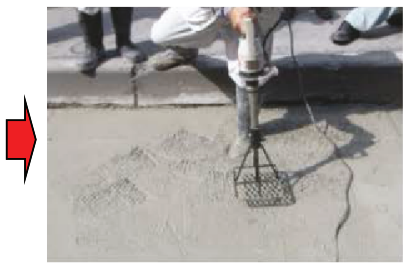

(d)

Figure 5: Example of thin-layer repair of upper layer of RC slab. (a) Degraded into aggregate. (b) Removal of damaged parts. (c) Removal of injured site. (d) Thin-layer repair.

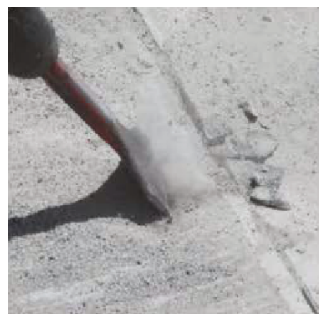

(a)

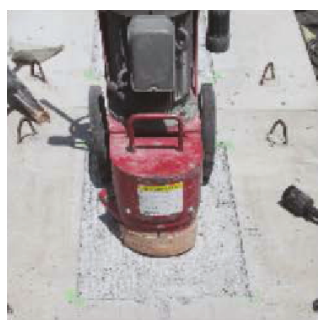

(b)

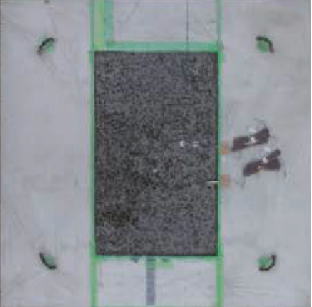

(c)

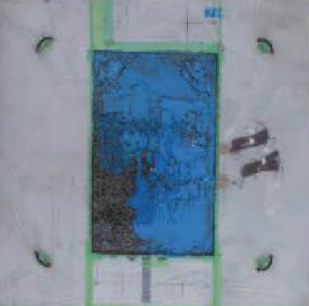

(d)

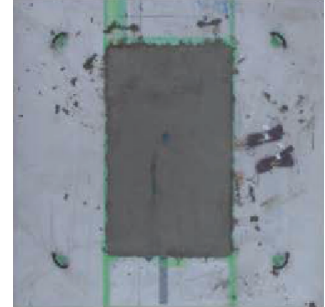

(e)

Figure 6: Procedure for manufacturing the RC slab specimen. (a) Removal of damaged parts. (b) Grinding of damaged parts. (c) Application of penetratable adhesive. (d) Application of bonding agent for placing. (e) Placing repair material and finish.

TABLE 6: The number of equivalent cycles and the reinforced equivalent running number used.

\begin{tabular}{|c|c|c|c|}
\hline & & RC-U-36 & RC-UF-45 \\
\hline RC slab & & $7,865,598$ & $7,865,598$ \\
\hline \multirow{2}{*}{ Primary repair (wet state) } & Equivalent runs, number of times & $1,685,974$ & $3,685,775$ \\
\hline & Reinforcement effect & - & 2.2 \\
\hline \multirow{2}{*}{ Secondary repair (wet state) } & Equivalent runs, number of times & $1,621,127$ & $3,250,670$ \\
\hline & Reinforcement effect & - & 2.0 \\
\hline \multirow{2}{*}{ Tertiary repair (dry state) } & Equivalent runs, number of times & $10,493,077$ & $42,350,384$ \\
\hline & Reinforcement effect & - & 4.0 \\
\hline \multirow{2}{*}{ Total until tertiary repair } & Equivalent runs, number of times & $21,665,776$ & $57,152,427$ \\
\hline & Reinforcement effect & - & 2.64 \\
\hline
\end{tabular}

of equivalent cycles for the third repair performed under dry conditions was $10.493 \times 10^{6}$, which resulted in punched shear failure. The cumulative number of the equivalent cycle count from 1 repair cycle to 3 repair cycles was $21.665 \times 10^{6}$, which resulted in a repair effect of 1.57 for the unrepaired slab plate. Wheel load data in Table 6 shows the number of equivalent cycles in the running wheel load running tests.

\subsubsection{Specimen RC-UM-45 Using New Repair Material} $U$-FM. The number of equivalent cycles of repairs using the proposed repair material U-FM and two kinds of adhesives was $3.685 \times 10^{6}$ in the first cycle of repair, $3.250 \times 10^{6}$ in the second cycle of repair, and $42.35 \times 10^{6}$ in the third cycle. This is 2.19 times more in the first cycle under dry conditions than with the conventional repairing method, 2.01 times in the second cycle, and 11.49 times in the third cycle. Also, the cumulative number of equivalent cycles until destruction in the $3 \mathrm{rd}$ cycle was $57.152 \times 10^{6}$. A reinforcement effect of 2.64 times that of the conventional construction method was obtained.

\subsection{Relation between Deflection and Number of Equivalent Cycles}

3.2.1. Specimen RC-U-36 Using Conventional Repair Material $U-M-36$. The residual deflection under initial loading was $1.42 \mathrm{~mm}$. For repairs with repair material U-M-36, in the first cycle, the cumulative number of equivalent cycles is $9.551 \times 10^{6}$, the cumulative deflection is $3.44 \mathrm{~mm}$, and the residual deflection is $1.96 \mathrm{~mm}$. The cumulative number of equivalent cycles in repair cycle 2 is $11.172 \times 10^{6}$, the cumulative deflection is $4.10 \mathrm{~mm}$, and the residual deflection is $2.74 \mathrm{~mm}$. In the third repair performed under dry conditions, damage on the repair surface was suppressed. Therefore, the cumulative number of equivalent cycles is $21.655 \times 10^{6}$ and 


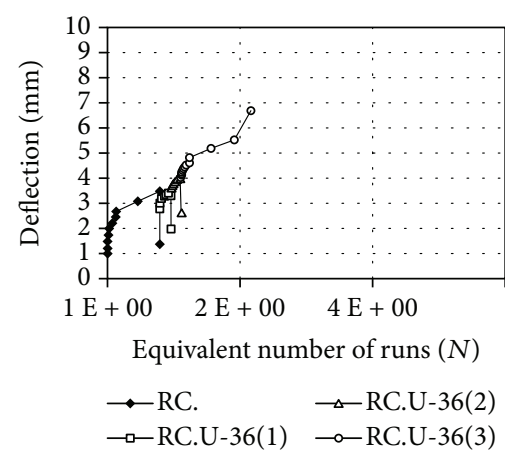

(a)
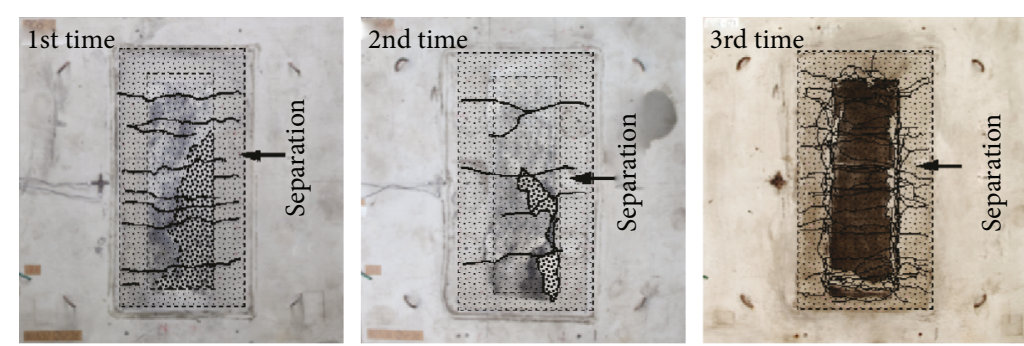

(b)

Figure 7: RC-U-36. (a) Relationship between deflection and number of equivalent cycles. (b) Condition of damage caused on the upper surface.

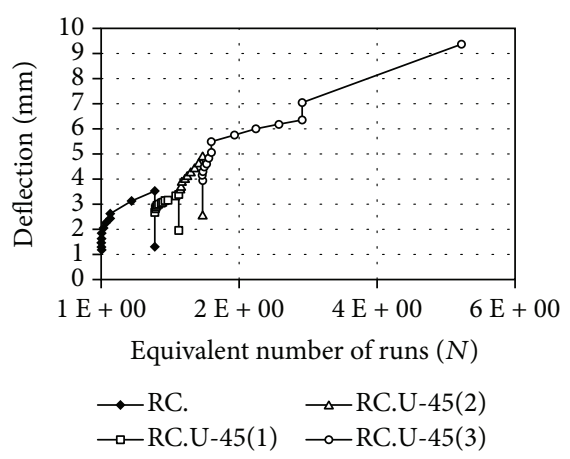

(a)
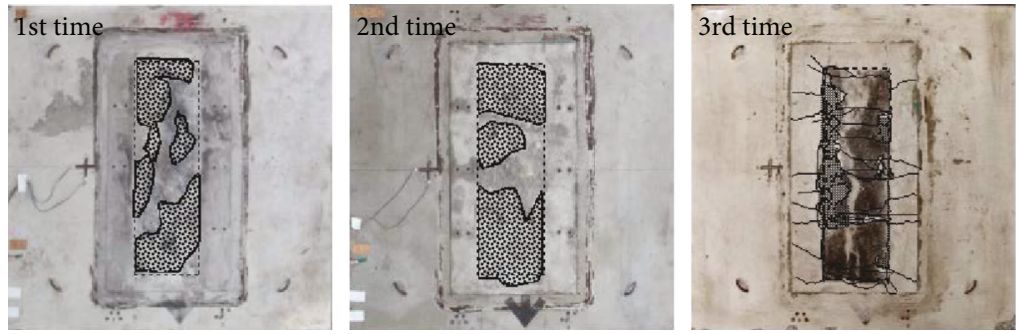

(b)

FIgURE 8: RC-UF-45. (a) Relationship between deflection and number of equivalent cycles. (b) Condition of damage caused on the upper surface.

the cumulative deflection is $6.65 \mathrm{~mm}$. Figure 7 (a) shows the relationship between deflection and the number of equivalent cycles. Figure 7(b) shows the condition of damage caused on the upper surface.

\subsubsection{About the Slab Using the Proposed Repair Material} U-FM Punching Shear Strength. Residual deflection due to the initial loading of the proposed repair material U-FM-45 and the test specimen to which two types of adhesives are applied is $1.31 \mathrm{~mm}$. The cumulative number of equivalent cycles in the first cycle of repair is $11.551 \times 10^{6}$, the cumulative deflection is $3.39 \mathrm{~mm}$, and the residual deflection is $1.90 \mathrm{~mm}$. Figure 8 (a) shows the relationship between deflection and the number of equivalent cycles. As shown in Figure 8(a), the damaged upper surface of the specimen after the runs showed irregularities due to wear, but no cracks are observed. The cumulative number of equivalent cycles in repair cycle 2 is $14.802 \times 10^{6}$, the cumulative deflection is $4.85 \mathrm{~mm}$, and the residual deflection is $2.53 \mathrm{~mm}$. The only damage is the unevenness of the road surface. The cumulative number of the equivalent cycles of repair cycle 3 under dry conditions is $57.152 \times 10^{6}$, and the cumulative deflection is $9.33 \mathrm{~mm}$. Since repair cycle 3 was conducted until the test specimen was destroyed by punching shear fracture, cracking occurred in the direction perpendicular to the axis on the upper surface of the test specimen. However, the number of equivalent cycles was four times that when using the conventional reinforcement method. These results confirm that the proposed repair method provides fatigue resistance and is practical for repairs using conventional reinforcement materials.

\section{Discussion}

4.1. Evaluation of Fatigue Resistance by the Number of Equivalent Cycles. A higher repair effect was obtained for $\mathrm{RC}$ slab test specimens repaired with the repair material UFM-45 by applying 2 types of adhesive at the top surface repair boundary of the $\mathrm{RC}$ slab than the repair effect for $\mathrm{RC}$ slab test specimens repaired with the conventional repair material U-M-36, by a factor of 2.2 for the first repair, a factor of 2 for the second repair, a factor of 4 for the third repair under dry conditions, and a factor of 2.64 at failure.

4.2. Evaluation of Crack Resistance. In these tests, after the deflection of the RC slab reached 1/400 of the span $L, 2$ cycles of repair were carried out under wet conditions and one cycle under dry conditions. After the wheel load running tests, multiple cracks were observed extending in the direction normal to the axial direction in the top surface of the slab that 
was repaired using the conventional repair material U-M-36. However, on the top surface of the test specimens repaired with the repair material U-FM-45 after applying the two types of adhesive to the boundary, the number of cracks in the direction normal to the axial direction was greatly reduced compared with the repair material U-M-36, although damage due to wear could be seen on the running surface. As a result, the fatigue durability was increased.

\section{Conclusions}

In this study, we investigated countermeasure technologies presuming that redamage is caused by delamination of the adhesion interface and cracking of the repair material, further supposing that rainwater and others, intrude and induce damage. The first countermeasure technology is a permeable adhesive for strengthening the adhesion interface. The second countermeasure technology is an adhesive for fresh concrete that firmly bonds the existing repair material with the new repair material. Finally, the third is the development and application of a repair material that has an elastic modulus equivalent to that of existing slabs and further improves resistance to cracking by using resin fibers to add toughness. In this research, we proposed a repair method that combines these technologies and confirmed that the method provides much greater fatigue resistance than the conventional construction method. The repair method using the repair material U-M-45 after applying the two types of adhesive obtained the same repair effect as was verified in the tests when applied to a real bridge. Namely, the fragile concrete surface was strengthened by applying the penetrable adhesive, and the repair material was firmly bonded to the existing slab at the joint by applying the epoxy adhesive. Therefore, for repairing thin layers of RC slabs, a repair method that applies dedicated repair material for repairing the slab after application of two types of adhesive is practical.

\section{Data Availability}

The data used to support the findings of this study are available from the corresponding author upon request.

\section{Conflicts of Interest}

The authors declare that there is no conflict of interest regarding the publication of this paper.

\section{Acknowledgments}

The authors are grateful for the advice from each of the engineers of Sumitomo Osaka Cement Co. Ltd and Kajimaroad Co. Ltd.

\section{References}

[1] T. Tamakoshi, M. Okubo, and K. Ikuta, "Analysis of periodic inspection results of highway bridges in Japan," in 25th US-Japan Bridge Engineering Workshop, pp. 61-68, Japan, 2009.
[2] H. Nakai, S. Matsui, T. Yoda, and A. Kurita, "Trends in steelconcrete composite bridges in Japan," Structural Engineering International, vol. 8, no. 1, pp. 30-34, 1998.

[3] Japan Road Association, Specifications and cmmentary for road bridges I, II, III, Yamato Planning Printing Co., Ltd., 2002.

[4] T. Kodama, O. Kamada, M. Nishi, Y. Zuzuki, and T. Fukute, "A study of bonded concrete overlays using epoxy adhesive in Japan," in Sixth International Conference on Maintenance and Rehabilitation of Pavements and Technological Control (MAIREPAV6), p. 111, Turin, Italy, 2009.

[5] K. Ito, J. Takahagi, H. Chiba, and Y. Suzuki, "Study on a countermeasure for improving the fatigue durability of existing orthotropic steel deck plates using SFRC pavement," in Proceedings of 5th China-Japan Workshop on Pavement Technologies (CJWPT 2009), pp. 221-226, China, 2009.

[6] T. Kodama, M. kagata, S. Higashi, K. Itoh, and Y. Ichinose, "Effect of reducing strains by SFRC pavement on Ohira Viaduct," in Proceeding of the 25th US-Japan Bridge Engineering Workshop. Tsukuba: Public Works Research Institute 2009, pp. 149-156, Tsukuba, Japan, 2009.

[7] T. Abe, H. Suzuki, Y. Kishi, and K. Nomoto, "The effect of adhesive on the fatigue resistance of RC slabs strengthened by SFRC upper surface thickness increasing method," Proceedings of Structural Engineering, vol. 59A, pp. 1084-1091, 2013.

[8] K. Ito, T. Abe, M. Fuchigami, N. Kozakai, and T. Kodama, “A study on fatigue durability of the top surface repair method using two types of adhesives for damaged RC slabs," in Fourth Conference on Smart Monitoring, Assessment and Rehabilitation of Civil Structures (SMAR 2017), p. 144, Zürich, Switzerland, 2017.

[9] T. Abe, T. Kida, M. Takano, and Y. Kawai, "Evaluation of the punching shear strength and fatigue resistance of road bridge RC slabs," Journal of Japan Society of Civil Engineers, Ser. A1 (Structural Engineering \& Earthquake Engineering (SE/EE)), vol. 67, no. 1, pp. 39-54, 2011.

[10] T. Abe, T. Kida, T. Sawano, A. Komori, and S. Hida, "Reinforcement effect and mechanical characteristics of CFS reinforced RC slabs with different number of layers," Theoretical and Applied Mechanics Japan, vol. 57, pp. 95-103, 2009.

[11] M. Takano, T. Abe, T. Kida, A. Kobayashi, and A. Komori, "Fatigue characteristics of CFS-reinforced RC slabs sustaining running vibration loads and running constant loads," Theoretical and Applied Mechanics Japan, vol. 58, pp. 31-39, 2010.

[12] S. Matui, "Design and construction of road bridge slabs and maintenance," Mori Kita Publishing, Inc, pp. 44-46, 2007. 


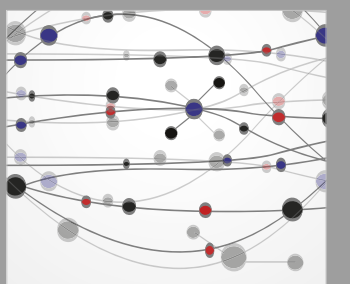

The Scientific World Journal
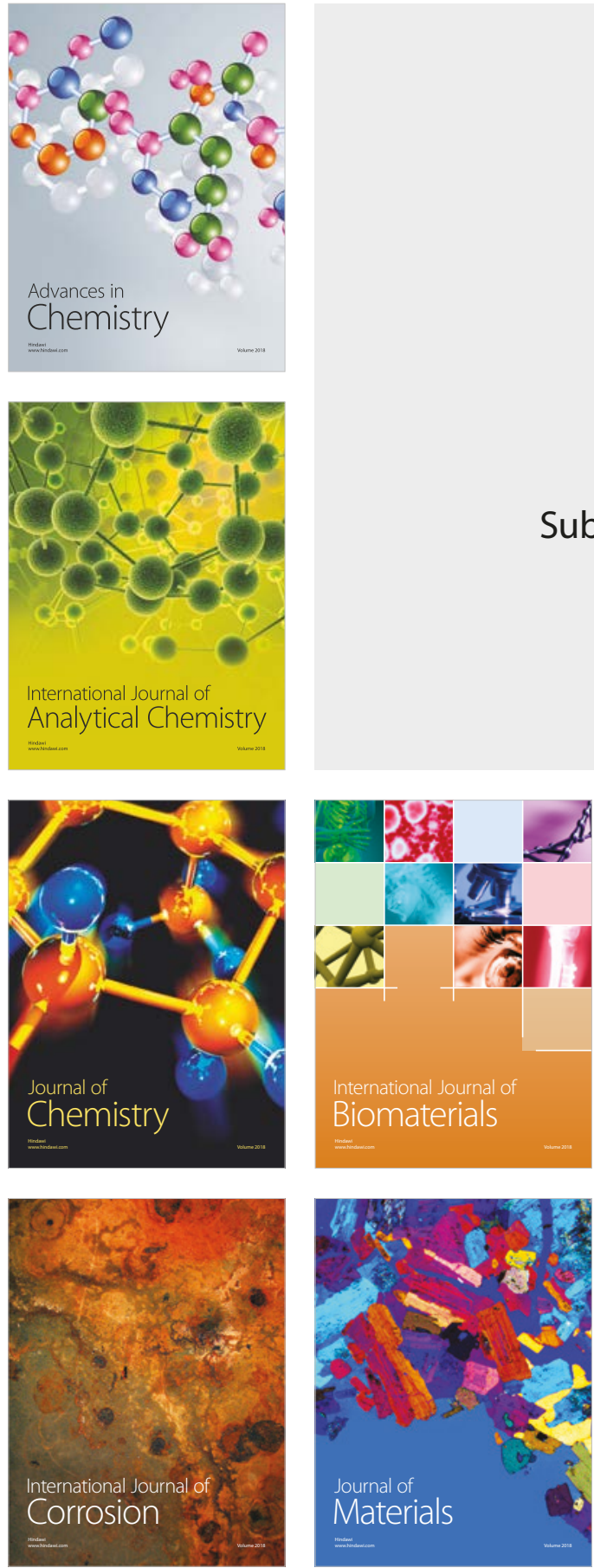

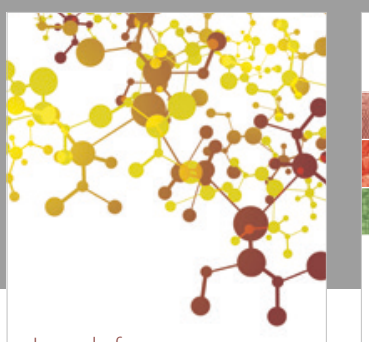

Journal of

Applied Chemistry
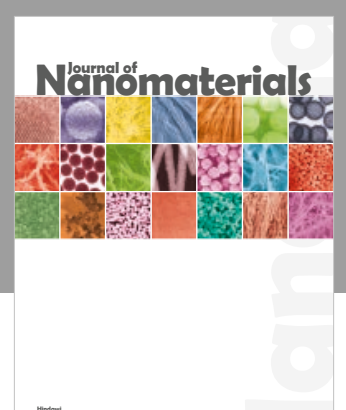

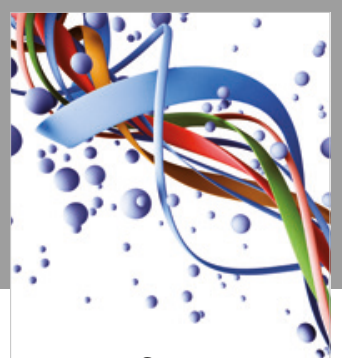

Scientifica

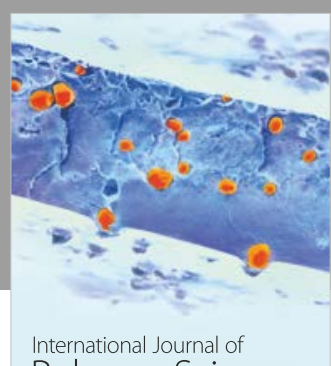

Polymer Science

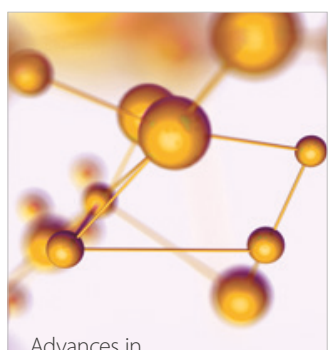

Physical Chemistry
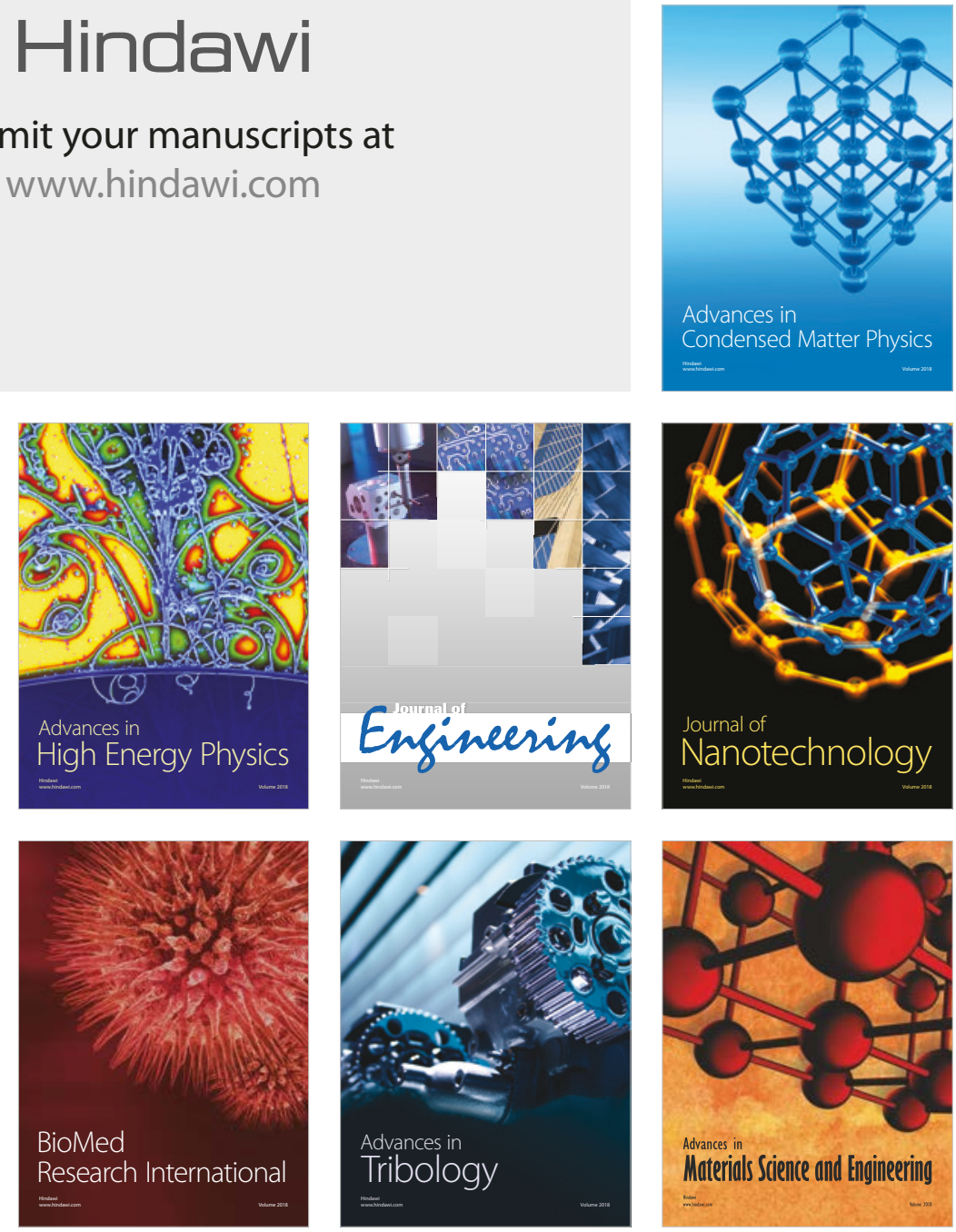